\title{
Role of Erythropoietin Induced Stem Cell Mobilization in the Repairing of Acute Kidney Injury Following Ischemia Reperfusion in Albino Rats: A Histological Study
}

\section{Original Article}

\author{
Samir M. Nada, Nagwa A.W. Ahmed, Eman Abas Farag and Rokia M. Hassan \\ Histology Department, Faculty of Medicine, Cairo University, Cairo, Egypt
}

\begin{abstract}
Background: The incidence of acute kidney injury (AKI), the new term for acute renal failure, has increased in recent years. Ischemia-reperfusion (IR) is one of the main causes of AKI. Erythropoietin (EPO) is a complex molecule, which regulates red blood cell production in the bone marrow. Recent studies provide evidence of potential therapeutic effect of EPO on AKI.

Aim of the Work: Investigate the role of EPO in mobilization of bone marrow derived stem cells and its role in repairing AKI.

Materials and Methods: This study included 32 adult male albino rats, divided into three groups; control, non-treated IR and EPO treated group. AKI was done by induction of IR via clamping both renal pedicles for 40 minutes and EPO 5000 $\mathrm{U} \mid \mathrm{kg}$ was injected in treated group once intraperitoneally immediately after IR. Rats were sacrificed 48 hours and 1 week after intervention, then renal sections were stained with hematoxylin \& eosin, PAS and immunohistochemically for CD34. Results: Erythropoietin improved the impaired kidney manifestations occurred by IR including increasing the reduced urea and creatinine levels, improved histological architecture of kidney. Also, increasing CD34 immunopositive hematopoietic and endothelial progenitor stem cells.

Conclusion: This work concluded that administration of EPO at time of renal IR resulted in enhanced mobilization of stem cells resulting in structural recovery and improved functions.
\end{abstract}

Revised: 15 January 2017, Accepted: 6 June 2017.

Key Words: Acute kidney injury, CD34, EPCs ischemia reperfusion, erythropoietin, hematopoietic stem cells.

Corresponding Author: Eman Abas Farag, Tel.:01140639636, E-mail: Emanabas@kasralainy.edu.eg

ISSN: 2536-9172, June 2017, Vol. 1, No 1

\section{INTRODUCTION}

Acute kidney injury (AKI) is a common, dangerous condition with high rates of mortality and morbidity. It has been also accompanied with increased length of hospital stay and adjusted ratios of 4.1 for hospital mortality and 2.0 for discharge ${ }^{[1]}$. Attacks of hypotension or surgical clamping of renal arteries are the major causes of acute tubular necrosis of kidney which is responsible for the majority of cases of AKI affecting renal functions ${ }^{[2]}$.

In humans, AKI is a precursor of chronic kidney disease (CKD) characterized by vasculopathy, fibrosis and progressive loss of function leading to renal failure ${ }^{[3]}$. Chronic kidney disease may represent inadequate regeneration following renal injury. However, kidney has enormous capacity for renewal and there are few therapies that promote kidney repair ${ }^{[4]}$.

Over a few decades, factors that promote reformation of injured kidney have been widely studied. By using animal models for kidney damage, the role of growth factors, transcription factors, hormones and extracellular matrix in this process has been examined. Therapeutic strategies, may potentially aimed to limit AKI and the development of $\mathrm{CKD}^{[5]}$.

Stem cells recognition in renal tissues is important for understanding tissue homeostasis and therapeutic applications. Previous researches revealed that the enhancements of mobilization, propagation and delivery of bone marrow-derived cells (BMDCs) as hematopoietic stem cells (HSCs) and endothelial progenitor cells (EPCs) to the kidney hold potential as entirely new approaches for the treatment of $\mathrm{AKI}^{[5]}$.

Erythropoietin (EPO) hormone receptor has been found in various non-hematopoietic tissues proposing that EPO might have important roles beyond erythrocyte production. Thus, EPO intake has been shown to ameliorate AKI and hastened functional recovery in response to renal insults as ischemia, ureteral obstruction, toxaemia and heatshock. Based on highly hopeful results, several trials 
of EPO therapy in ischaemic or toxic AKI are currently underway ${ }^{[6]}$. This study was designed to investigate role of EPO in mobilization of CD34 positive bone marrow derived stem cells and its possible role in AKI caused by ischemia reperfusion in adult male albino rats monitored by histopathological, serological and morphometrical studies.

\section{MATERIALS AND METHODS}

\section{A-Materials:}

Drug: Erythropoietin (EPO): Epoetin (Sedico), 5000 $\mathrm{U} \mid \mathrm{kg}$ was injected once intraperitoneal (IP) immediately after IRI ${ }^{[6]}$.

Animals: This study included 32 adult male albino rats, 180- 200 grams body weight. Rats were bred in Animal House of Kasr Al-Ainy, Cairo, Egypt, according to guidelines of the Animal Ethical Committee of Faculty of Medicine, Cairo University. Each group was kept in separate wire cage at room temperature, fed ad libitum and allowed access for free water supply. Rats were divided into three groups as follows:

Group I (control group): 8 rats were subdivided equally into:

-Subgroup Ia (plain control): not exposed to operation nor EPO.

-Subgroup Ib (Sham-operated Group): subjected to sham operation.

Two rats from each subgroup were sacrificed for each experimental subgroup.

Group II (non treated group): 12 rats subjected to renal ischemia reperfusion injury (IRI). They were sacrificed as follows:

-Subgroup IIa: 6 rats were sacrificed after 48 hours of reperfusion.

-Subgroup IIb: 6 rats were sacrificed after one week of reperfusion.

Group III (Erythropoietin-treated group): 12 rats subjected to IRI and immediately received EPO injection. They were sacrificed as follows:

-Subgroup IIIa: 6 rats were sacrificed after 48 hours of reperfusion.

-Subgroup IIIb: 6 rats were sacrificed after one week of reperfusion.

\section{B-Methods:}

Induction of ischemia-reperfusion AKI by renal pedicle ligation:

Ischemia-reperfusion AKI was induced in ketamine xylasine-anesthetized animals. Midabdominal laparotomy was performed after the disinfection of abdominal wall by povidone iodine (Betadine). Kidneys were exposed and renal pedicles were clamped for 40 minutes by smoothedged surgical clamp. Reflow was visually confirmed. $4 \mathrm{ml}$ warm normal saline was given IP before abdominal closure to avoid ileus. Topical Garamycin cream was applied after wound closure to reduce risk of wound infection ${ }^{[7]}$.

\section{Sham operation:}

A procedure that is performed similar to the operation of ischemia-reperfusion AKI induction but omits the renal pedicle ligation ${ }^{[8]}$.

\section{Laboratory investigations:}

Blood samples, using capillary tubes, were drawn from retro-orbital veins. Serum urea and creatinine were measured for all rats, before and after intervention throughout period of experiment. Serum urea and creatinine were measured at Biochemistry Department, Kasr Al-Ainy Medical School as follows:

Day 0: before induction of IR AKI.

Day 1: 24 hours after induction of IR AKI.

Day 2: 48 hours after induction of IR AKI.

Day 7: 7 days after induction of IR AKI.

Evaluation of the morphological changes of kidney after ischemia-reperfusion AKI and the effect of erythropoietin administration:

At the end of each experimental period, right kidney from each animal was immediately dissected, fixed in 10 $\%$ buffered formalin solution for 48 hours, dehydrated in ascending grades of ethanol and embedded in paraffin. Serial sections of $7 \mu \mathrm{m}$ thickness were cut, mounted on slides and subjected to the following:

Hematoxylin \& Eosin (H\&E) $\operatorname{stain}^{[9]}$.

Periodic Acid Schiff Reaction (PAS) to demonstrate basal lamina and brush border as a measure of tubular injury ${ }^{[9]}$.

-Immunohistochemichal staining using anti CD34 antibody. It's a marker for hematopoietic stem cells (HSCs), endothelial progenitor cells (EPCs) \& small vessels endothelium $^{[5-10]}$.Paraffin sections were deparaffinized, rehydrated, incubated with hydrogen peroxide for 30 minutes then rinsed in PBS. Sections were incubated for one hour with 2 drops $(=100 \mu \mathrm{l})$ of the primary antibody CD34 Ab-1, Clone QBEnd/10 (Lab Vision Corporation Laboratories, CA 94539, USA, catalogue number MS363- R7). Immunostaining was completed by the use of Histostain SP kit detection system that includes serum blocking solution, a biotinylated secondary antibody, a horseradish peroxidase streptavidin and a substrate chromogen mixture to demonstrate antigen in cells and tissues (LAB-SA system, Zymed Laboratories Inc, San Francisco, CA 94080, USA, cat no 95- 9643). Mayer's hematoxylin purchased from Labvision Thermoscientific USA (cat no TA- 060- MH) was used for counter staining. CD34 positive cells showed brown cytoplasmic deposits. Tonsil sections were used as positive control specimens \& 
one of the kidney sections was used as a negative control by passing the step of applying the primary antibody ${ }^{[1]}$.

\section{Morphometric study to measure the following parameters:}

Mean numbers of affected Malpighian renal corpuscles in $H \& E$ stained sections at a magnification of $x 100$.

Mean area percent of PAS positive material in PASstained sections at a magnification of $\mathrm{x} 400$.

Mean numbers of CD34 immunopositive cells in renal interstitium per high power field at a magnification of $\times 400$.

All measurements were done Using " Leica Quin 500" software image analyzer computer system (Leica image system Ltd; Cambridge, England) present in the Histology Department, Faculty of Medicine, Cairo University and was detected in 10 non-overlapping randomly chosen fields for each animal.

Statistical analysis: was done for serum levels of urea and creatinine and for the morphometric results. Data were expressed as mean \pm SD. Data were statistically analyzed using statistical package SPSS version 16 (SPSS Inc., Chicago, USA). Comparisons between groups were done using ANOVA (analysis of variance) followed by post hoc test for multiple comparisons between each 2 groups. The results were considered significant when $p<0.05$.

\section{RESULTS}

No mortality occurred throughout the experimental period.

\section{Laboratory results:}

\section{Serum creatinine and urea levels in all groups}

Mean serum creatinine and urea showed no significant difference between all subgroups and corresponding control on day 0 . On day 1 (24 hours after IRI), all experimental subgroups exhibited a significant increase when compared to corresponding control, but its level in subgroups IIIa \& IIIb significantly decreased when compared with subgroups IIa \& IIb respectively. On day 2 (48 hours after IRI), mean Serum creatinine and urea for all experimental subgroups were significantly increased when compared to corresponding control, however these levels for subgroups IIIa and IIIb showed a significant decrease when compared to subgroups IIa and IIb respectively. On day 7 (1 week after IRI), both subgroups IIb and IIIb revealed a significant increase when compared to corresponding control. Subgroup IIb showed non significant decrease compared to subgroup IIa while, subgroup IIIb showed significant decrease compared to subgroup IIIa. Subgroup IIIb also, showed a significant decrease when compared to subgroup IIb (Table 1)

\section{Histological and immunohistochemical results}

Examination of renal sections in subgroups Ia and $\mathrm{Ib}$ revealed no histological differences. So they are discussed as control group (group I).

\section{Hematoxylin and eosin stained sections}

\section{Group I (control group):}

Histological examination of renal sections from control rats (group I) showed normal architecture. Sections of renal cortex showed Malpighian renal corpuscles (MRCs) formed of tuft of capillaries (glomeruli) and Bowman's spaces (Fig. 1A) that appeared in all sections regular and narrow. Proximal convoluted tubules (PCT) showed narrow lumen and were lined with simple high cuboidal cells with rounded basal nuclei and acidophilic cytoplasm. Distal convoluted tubules (DCT) showed wider lumen and were lined with simple low cubical cells with rounded central nuclei (Fig. 1B). Sections of renal medulla showed the collecting tubules with narrow lumens and normal arrangement pattern (Fig. 1C). They were lined with simple cuboidal epithelium (Fig. 1D).

\section{Group II (non treated group)}

\section{Subgroup IIa (IRI, 48 hours):}

Examination of renal sections revealed many histopathological changes. Renal cortex showed MRCs with widening of Bowman's spaces. Some glomeruli appeared distorted and shrunken. Exudates accumulation in Bowman's spaces and glomerular capillary degeneration were also noticed in some of them. Many tubules (proximal and distal) demonstrated a detachment of their cells from their basement membranes (Fig. 1E). Nuclei of some cells lining tubules appeared fragmented, others were pyknotic with peripheral condensed chromatin. Hyaline casts were seen in the lumina of some tubules (Fig. 1-F). Most of cortical tubules showed cytoplasmic vaculation. Marked inflammatory infiltration inbetween cortical tubules were seen (Fig. 2-A). Sections of renal medulla revealed many collecting tubular cells with widely distributed marked cytoplasmic vacuolation and others with deeply acidophilic cytoplasm. Nuclei of some lining cells appeared pyknotic while others showed peripheral condensed chromatin (Figs. 2-B and 2-C). Peritubular capillary congestion and cellular debris inside lumina of some tubules were also noticed (Fig. 2-C).

\section{Subgroup IIb (IRI, 1 week)}

Examination of renal sections demonstrated some glomeruli are shrunken with partial widening of Bowman's spaces. Other glomeruli showed marked distortion or complete loss of the glomerular tufts. Tubular epithelial cells appeared detached from their underlying basement membrane. Hyaline casts were demonstrated in lumens 
of some tubules (Figs. 2-D and 2E). Cytoplasm of tubular cells appeared vacuolated and some nuclei appeared pyknotic (Fig. 2-F). Medullary sections examination of subgroup IIb revealed many areas of distorted tubules with cellular debris, congestion of minor blood vessels inbetween renal tubules with extravasation of RBCs. Many tubular cells showed pyknotic nuclei (Fig. 3-A).

\section{Group III (EPO-treated group):}

\section{Subgroup IIIa (EPO, 48hours):}

Examination of cortical sections detected apparently normal histological architecture of most of MRCs with formed glomerular tufts, but few showed shrunken glomeruli. Many proximal and distal tubules revealed normal histological architecture. Some tubules demonstrated dilatation (Figs. 3-B and 3-C). Medullary sections examination of subgroup IIIa showed mild congestion of peritubular blood capillaries. Many cells in collecting tubules showed pyknotic nuclei (Fig. 3-D).

\section{Subgroup IIIb (EPO, 1 week):}

Cortical sections showed renal corpuscles with normal histological picture including well-formed capillary tufts and well organized narrow Bowman's spaces. Many of proximal and distal tubules exhibited normal histological architecture, but some tubular cells still have deeply acidophilic cytoplasm with pyknotic nuclei. No peritubular congestion was noticed (Fig. 3-E). Medullary sections in subgroup IIIb exhibited normal histological appearance of most collecting tubules. Some tubular cells exhibited dark acidophilic cytoplasm with pyknotic nuclei were also noticed (Fig. 3-F).

\section{PAS stained sections:}

\section{Group I (control group):}

Examination of renal cortical sections of control group revealed the cortical tubules with preserved brush border and continuous basal laminae. PAS highlighting the basement membranes of the glomerular capillary loops was seen along with that of the parietal epithelial cells of Bowman's capsules (Fig. 4-A)

\section{Group II (non-treated group):}

\section{Subgroup IIa (IRI, 48 hours)}

Sections in renal cortex showed partial or complete loss of the brush borders in most of the tubules. Basal laminae were interrupted in some parts of renal tubules while preserved in other parts. Hyalinization appeared in the lumen of some tubules (Fig. 4B).

\section{Subgroup IIb (IRI, 1 week)}

Sections in renal cortex revealed complete loss of brush borders and interrupted basal laminae in most of the tubules. Basal laminae of the parietal layer of Bowman's capsules were apparently thickened in some areas (Fig. 4C).

\section{Group III (EPO-treated group):}

\section{Subgroup IIIa (EPO, 48 hours)}

Sections of renal cortex demonstrated partial loss of the brush border in some of the tubules while others showed interrupted basal laminae. Thickened parts of the basal laminae of the parietal epithelium of Bowman's capsules were also seen (Fig. 4D).

\section{Subgroup IIIb (EPO, 1 week)}

Examination of renal sections detected most of cortical tubules with preserved brush border. PAS stained basal laminae appeared continuous in most of the renal tubules. Also, PAS highlighting the basement membranes of glomerular capillary loops was seen along with the parietal epithelial cells of Bowman's capsules (Fig. 4E)

\section{Immunohistochemical results}

\section{Group I (control group):}

Renal sections of control group stained with anti-CD34 antibody revealed positive cytoplasmic immunoreactivity in the endothelial cells lining glomerular blood capillaries and in those lining the peritubular capillaries (Fig. 5A).

\section{Group II (non-treated group):}

Renal sections of subgroup Пa (IRI, 48hours) immunostained with antiCD34 antibody revealed decreased immunoreactivity in cells lining glomerular\& peritubular blood capillaries (Fig. 5B). Renal sections of subgroup Пb (IRI, 1 week) showed few CD34 positive cells with brown cytoplasmic deposits in-between renal tubules. Mild positive immunoreactivity was observed in glomerular and peritubular capillaries (Fig. 5C).

\section{Group III (EPO-treated group):}

Renal sections of subgroup ПIа (ЕРО, 48hours) detected numerous CD34 positive immunoreactive cells accumulated in renal interstitium mainly in areas near glomerular and peritubular capillaries. They appeared branched with brown cytoplasmic immunoreaction and rounded nuclei (Figs. 5D and 5E). Renal sections of subgroup $\Pi \mathrm{Ib}$ (EPO, 1 week) demonstrated the presence of few CD34 positive immunoreactive cells in interstitium. Also, positive immunoreaction was detected in endothelial lining of renal glomerular capillaries and peritubular capillaries (Fig. 5F). 


\section{Morphometric results}

\section{Mean numbers of affected glomeruli $( \pm S D)$ in all groups: ( Table 2)}

The mean numbers of affected glomeruli in subgroups IIa, IIb, IIIa and IIIb were significantly increased when compared to control. These mean numbers represented, in subgroups IIIa and IIIb, a significant decrease as compared to subgroups IIa and IIb respectively. Meanwhile non significant decrease was detected between subgroup IIb compared to subgroup IIa.

\section{Mean area percent of $P A S$ positive material $( \pm S D$ in all groups): (Table 2)}

The mean area percent of PAS positive material in subgroups IIa, IIb, IIIa and IIIb showed a significant decrease when compared to control. It revealed a significant increase in subgroups IIIa when compared to subgroup IIa. It also, showed in subgroup IIIb a significant increase when compared to subgroups IIa, IIb and IIIa. Meanwhile non significant increase was detected between subgroup IIb compared to subgroup IIa.

Mean numbers of CD34 immunopositive cells $( \pm S D)$ in renal interstitium in all groups: (Table 2$)$

Compared to control group, mean number of CD34 immunopositive cells detected in renal interstitium increased in all experimental subgroups but was only significant in subgroup IIIa and subgroup IIIb. Also, mean numbers of CD34 immunopositive cells in subgroup IIIa showed significant increase versus subgroup IIa, subgroup IIb \&subgroup IIIb. The mean numbers of CD34 immunopositive cells in subgroup IIb showed non significant increase compared to subgroup IIa\& non significant decrease compared to subgroup IIIb.

Table 1: Comparison between the values of mean serum creatinine and mean serum urea $( \pm \mathrm{SD})$ in the studied groups

\begin{tabular}{|c|c|c|c|c|c|c|}
\hline Day & & Group I & Subgroup IIa & Subgroup IIb & Subgroup IIIa & Subgroup IIIb \\
\hline \multirow[t]{2}{*}{ Day 0} & Creatinine & $0.49 \pm 0.05$ & $0.49 \pm 0.03$ & $0.50 \pm 0.03$ & $0.50 \pm 0.05$ & $0.50 \pm 0.01$ \\
\hline & Urea & $35.85 \pm 4.35$ & $35.79 \pm 4.71$ & $35.59 \pm 4.89$ & $35.32 \pm 4.16$ & $35.04 \pm 5.15$ \\
\hline \multirow[t]{2}{*}{ Day 1} & Creatinine & $0.50 \pm 0.26$ & $1.90 \pm 0.59^{*}$ & $1.87 \pm 0.15^{*}$ & $0.92 \pm 0.02 * \#$ & $0.92 \pm 0.02 * \#$ \\
\hline & Urea & $36.08 \pm 3.98$ & $73.08 \pm 3.74 *$ & $73.28 \pm 3.37 *$ & $58.24 \pm 1.79^{* \#}$ & $58.1 \pm 1.43^{*} \#$ \\
\hline \multirow[t]{2}{*}{ Day 2} & Creatinine & $0.50 \pm 0.02$ & $2.14 \pm 0.11^{*}$ & $2.26 \pm 0.20 *$ & $0.65 \pm 0.01 * \#$ & $0.66 \pm 0.01 * \#$ \\
\hline & Urea & $36.12 \pm 3.56$ & $96.04 \pm 0.68^{*}$ & $96.01 \pm 0.66^{*}$ & $52.58 \pm 0.60 * \#$ & $52.55 \pm 0.58^{* \#}$ \\
\hline \multirow[t]{2}{*}{ Day 7} & Creatinine & $0.51 \pm 0.02$ & & 1.90土0.08*@ & & $0.60 \pm 0.01 * \#$ \\
\hline & Urea & $36.04 \pm 3.71$ & & 94.02×1.08*@ & & $50.17 \pm 0.59 * \#$ \\
\hline \multicolumn{7}{|c|}{$\begin{array}{l}\text { * Significantly different from the corresponding value of the control group at } P<0.05 \text {. } \\
\text { \# Significantly different from corresponding value of subgroup II at } P<0.05 \text { on the same day. } \\
\text { @ Non significantly different from the corresponding value of subgroup IIa (day } 2 \text { ) at } P>0.05 \text {. } \\
\text { « Significantly different from the corresponding value of subgroup IIIa (day } 2 \text { ) at } P<0.05 \text {. }\end{array}$} \\
\hline
\end{tabular}


Table (2): The mean numbers of affected glomeruli, the area percent of PAS positive material and mean numbers of CD34 positive stem cells $( \pm \mathrm{SD})$

\begin{tabular}{|c|c|c|c|}
\hline Groups & $\begin{array}{l}\text { mean numbers of affected } \\
\text { glomeruli } \pm \text { SD }\end{array}$ & $\begin{array}{l}\text { mean area percent of PAS } \\
\text { positive material } \pm \mathrm{SD}\end{array}$ & $\begin{array}{l}\text { mean numbers of CD34 } \\
\text { positive cells } \pm \text { SD }\end{array}$ \\
\hline Group I & $1 \pm 0.3$ & $29.40 \pm 3.88$ & $1.10 \pm 0.84$ \\
\hline Subgroup IIa & $3.4 \pm 0.54 *$ & $9.86 \pm 1.72 *$ & $1.7 \pm 0.94$ \\
\hline Subgroup IIb & $3 \pm 0.7 * \&$ & $11.50 \pm 2.33 * \&$ & $2.92 \pm 0.82 \& \Delta$ \\
\hline Subgroup IIIa & $2 \pm 0.7 * \#$ & 15.62士3.16*@ & $7.55 \pm 1.26^{*} \square$ \\
\hline Subgroup IIIb & $1.6 \pm 0.12 * \#$ & $26.47 \pm 3.52 *$ & $4.22 \pm 0.99 *$ \\
\hline
\end{tabular}

\footnotetext{
* Significantly different from the corresponding value of control group at $P<0.05$.

\# Significantly different from the corresponding values of subgroups IIa \& IIb at $P<0.05$ on the same day.

(a) Significantly different from the corresponding value of subgroup IIa at $P<0.05$.

\& Non Significantly different from the corresponding value of subgroup IIa at $P>0.05$.

$\Delta$ Non significantly different from the corresponding value of subgroup IIIb at $P>0.05$.

- Significantly different from the corresponding values of subgroups IIa, IIb \& IIIa at $P<0.05$

$\square$ Significantly different from the corresponding values of subgroups IIa, IIb\& IIIb at $P<0.05$.
}


Fig. 1: Renal cortical section in control group (H\&E) showing (A): Malpighian renal corpuscles formed of glomeruli (G) and Bowman's spaces (arrow heads). PCT (P) \& DCT (D) (x200). (B): glomeruli (G), Bowman's spaces (arrow heads), PCT (P) appeared narrow, lined with high cuboidal cells with homogenous acidophilic cytoplasm \& DCT (D) are wide and lined with low cubical cells (x400). (C): collecting tubules of renal medulla with narrow lumina and normal arrangement pattern (x200). (D): higher magnification of the previous figure (x400). Renal cortical section in subgroup IIa showing (E): Malpighian renal corpuscle with accumulated exudate (E) and complete degeneration of glomerular capillary tuft $(\mathrm{G})$ \& detached tubular cells from their basement membrane (wavy arrows) (x200). (F): dense hyaline casts in lumina of some tubules (green astrix), distorted Bowman's space (arrow head) and tubular lumen (green arrow). Some tubular cell nuclei are fragmented (yellow arrow), pyknotic (black arrow) or with peripheral chromatin condensation (curved arrow) 

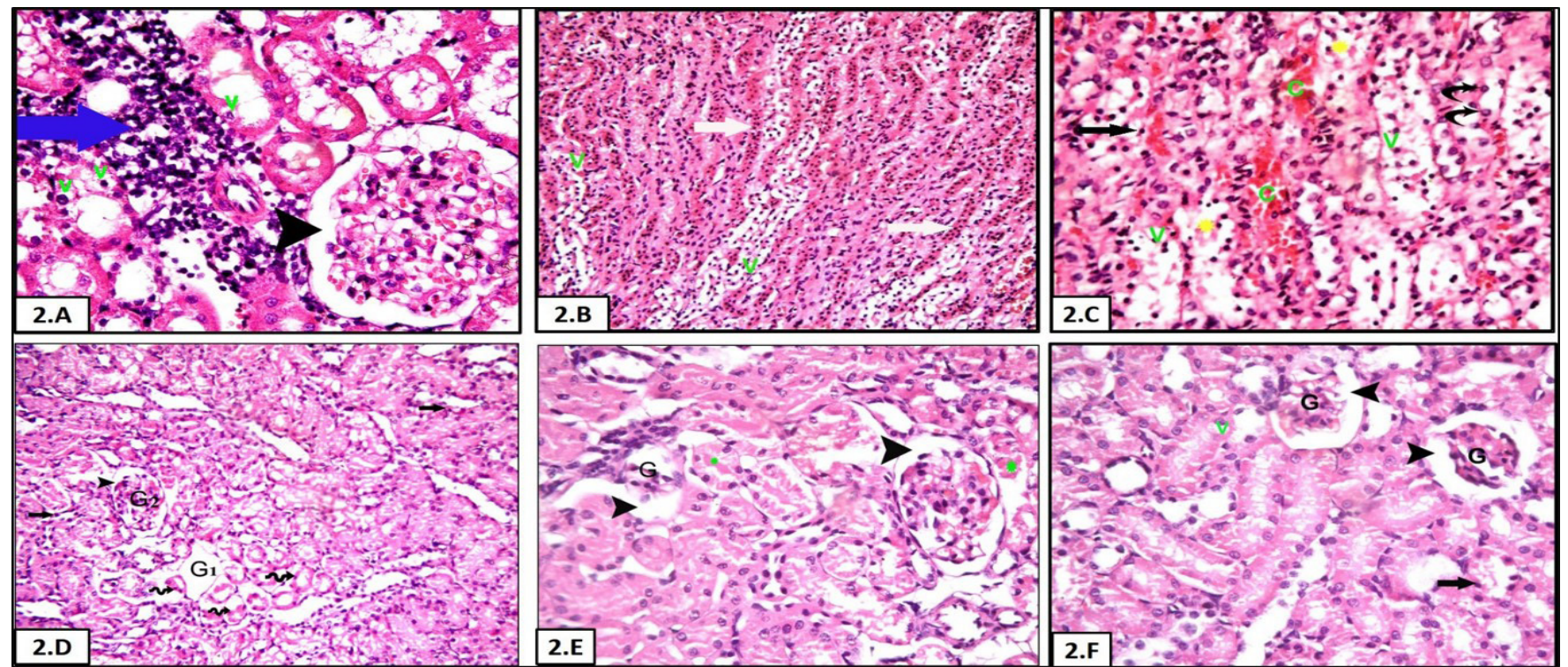

Fig. 2: Renal cortical section in subgroup IIa showing (A): widened Bowman's space (arrow head), marked inflammatory infiltrate (blue arrow) and cytoplasmic vaculation in some tubular cells (V) (x400). (B): many tubular cells with marked cytoplasmic vaculation (V) \& others with deeply acidophilic cytoplasm (white arrows) (x200). (C): peritubular capillary congestion (C) and cellular debris (yellow astrixes) in lumina of some tubules. Many tubular cells appeared with marked cytoplasmic vaculation (V), pyknotic nuclei (black arrow) and others with peripheral condensation of nuclear chromatin (curved arrows) (x400). Renal cortical section in subgroup IIb (H\&E) showing (D): Malpighian renal corpuscle with complete loss of glomerular tuft (G1), preserved glomerulus (G2) and distorted Bowman's space (arrow head). Detached tubular epithelial cells from their underlying basement membrane (wavy arrows) \& pyknotic nuclei (black arrows) are also seen (x200). (E): shrunken renal glomerulus (G), wide Bowman's spaces (arrow heads) \& hyaline casts (green astrixes) in tubular lumen (x400). (F): Malpighian renal corpuscles with shrunken glomeruli $(\mathrm{G})$ and widened Bowman's spaces (arrow heads). Cytoplasmic vacuolation (V) in lining tubular cells \& some pyknotic nuclei (black arrow) are also, seen
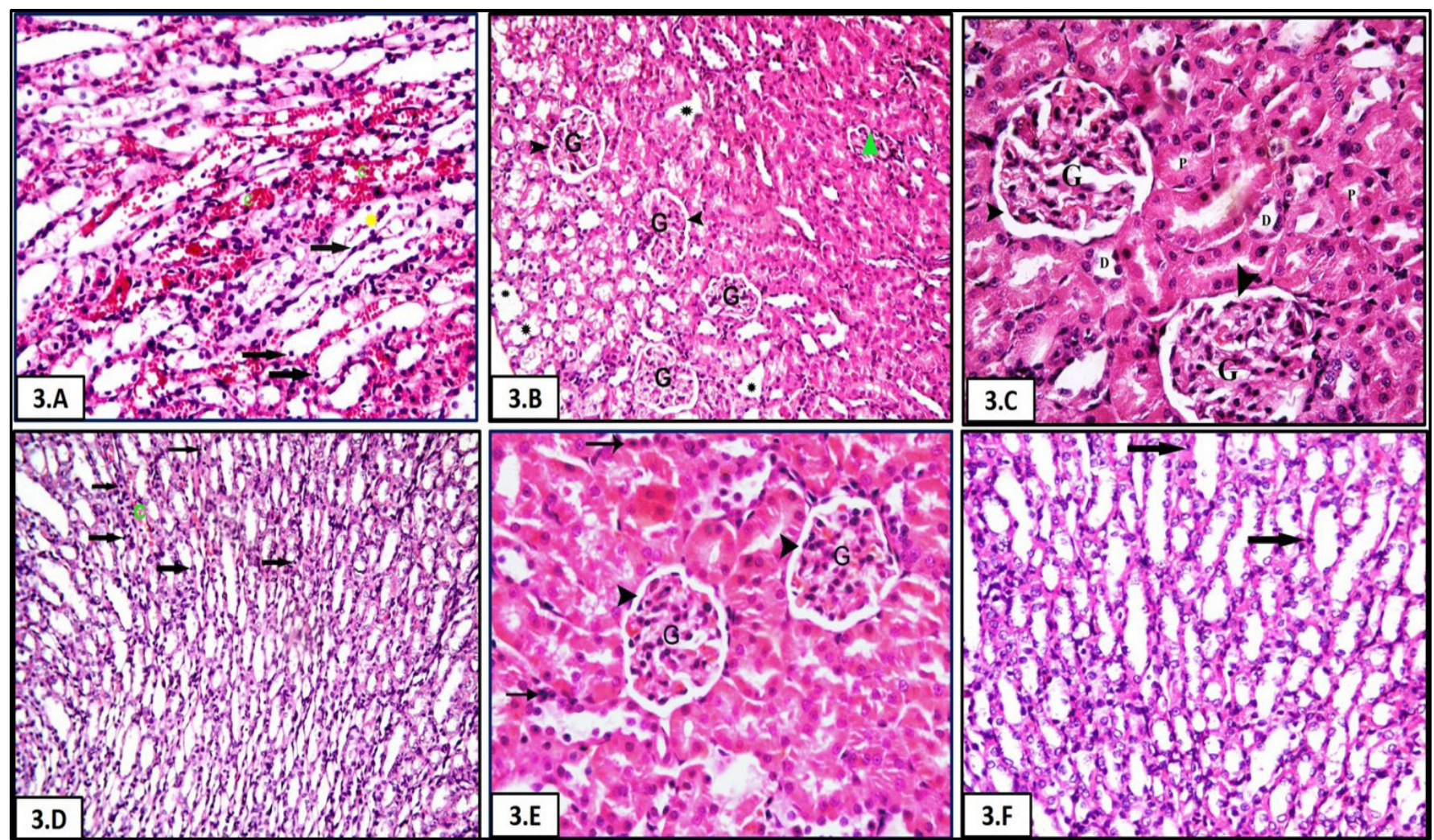

Fig. 3: (A): Renal medulla of subgroup IIb showing distorted tubules with cellular debris (yellow astrix), peritubular blood capillary congestion (C) with extravasated RBCs and pyknotic nuclei (black arrows) in tubular cells (x400). Renal cortical section in subgroup IIIa showing (B): Most Malpighian renal corpuscles with formed glomerular tufts $(\mathrm{G})$ and narrow Bowman's spaces (arrow heads). Few shrunken glomeruli (green triangle) \& some dilated tubules (black astrixes) are also, seen (x200). (C): Malpighian renal corpuscles with formed glomerular tufts (G) and Bowman's spaces (arrow heads). Many PCT (P) \& DCT (D) appeared normal (x400). (D): mild peritubular congestion (C)\& Many tubular cells with pyknotic nuclei (black arrows). (x200). Renal cortical section in subgroup IIIb showing (E): Malpighian renal corpuscles with well organized glomerular tufts $(\mathrm{G})$ and narrow Bowman's spaces (arrow heads). some tubular cells have deeply acidophilic cytoplasm with pyknotic nuclei (black arrows) (x400). (F): most collecting tubules are well organized, some tubular cells with dark acidophilic cytoplasm and pyknotic nuclei are noticed (black arrows)

$(\mathrm{x} 400)$ 

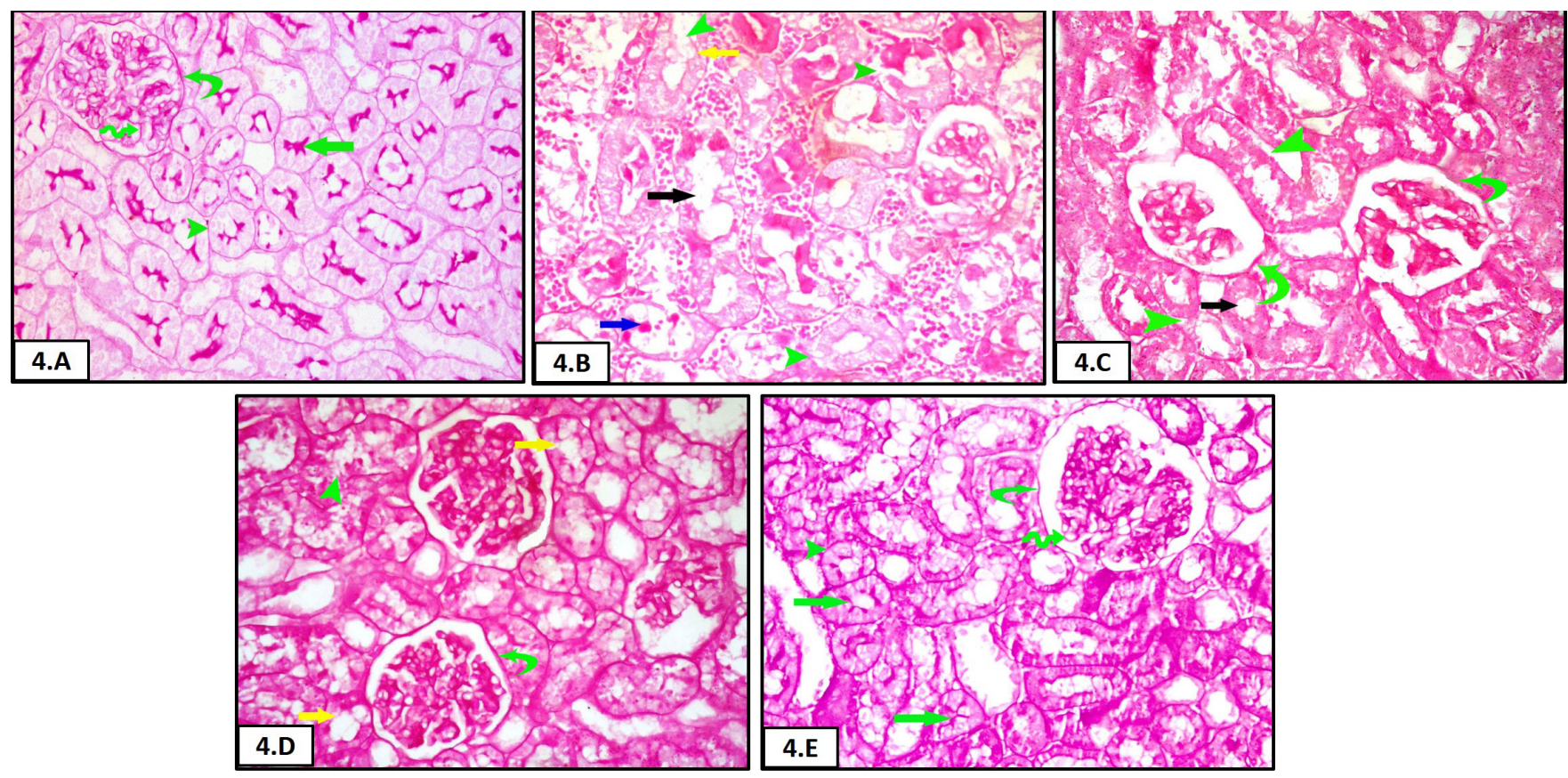

Fig. 4: Renal cortical section (PAS $\mathrm{x} 400$ ) in (A): control group showing multiple tubules with preserved brush border (green arrow) and continuous basal lamina (arrow head). PAS stained basement membranes of glomerular capillary loops (wavy arrow) are seen along with parietal layers of Bowman's capsule (curved arrow). (B): subgroup IIa showing absent brush border (black arrow) in most of cortical tubules and partial loss (yellow arrow) in others, interrupted basal laminae are seen in some tubules (arrow heads) \& hyalinization appears in lumina of some tubules (blue arrow). (C): subgroup IIb showing most of tubules with absent brush border (black arrow) \& interrupted basal laminae (arrow heads). Apparent thickened basal laminae of parietal epithelium of Bowman's capsules is seen in some areas (curved arrows). (D): subgroup IIIa showing some tubules with partial loss of brush border (yellow arrows) and others with interrupted basal laminae (arrow head). Thickened parts of basal laminae of parietal epithelium of Bowman's capsules are seen (curved arrow). (E): subgroup IIIb showing preserved brush borders (green arrows) of most tubules with continuous basal laminae of tubules (arrow head), glomerular capillary loops (wavy arrow) and parietal epithelial cells of Bowman's capsules (curved arrow)

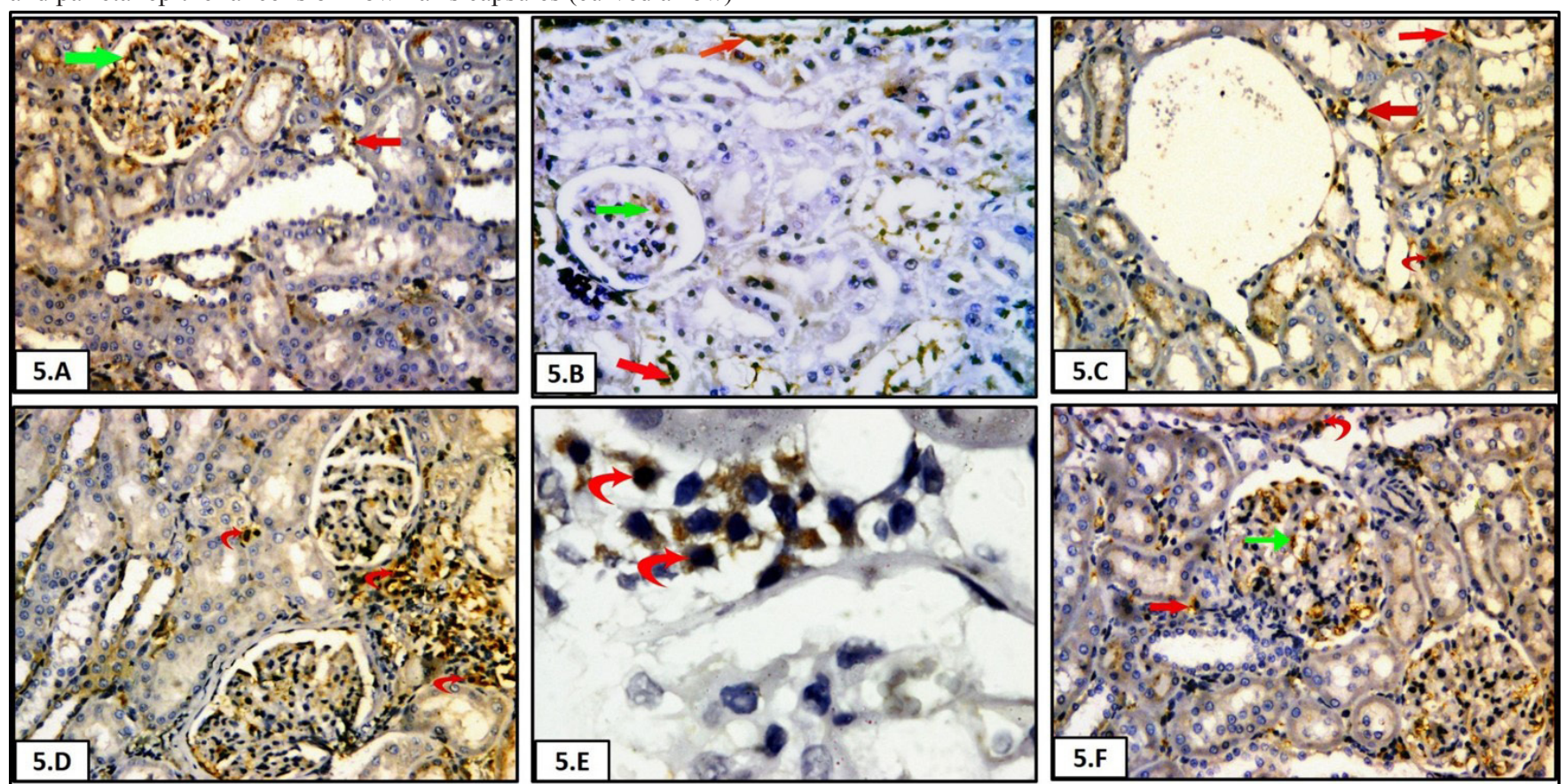

Fig. 5: CD34 immunostained renal cortical section in (A): control group showing positive immunoreactivity in the form of brown cytoplasmic deposits in endothelial cells lining glomerular (green arrow) and peritubular capillaries (red arrow) (x200). (B): subgroup Пa showing positive cytoplasmic immunoreactivity in endothelial cells lining some peritubular blood vessels (red arrows) \& decreased reactivity in those lining glomerular capillaries (green arrow) (x200). (C): subgroup Пاb showing few CD34 positive cells between renal tubules (curved arrow). Positive cytoplasmic immunoreaction in peritubular capillaries (red arrows). Negative CD34 immunoreaction in remaining parts of destroyed glomerulus (x200). (D): subgroup ПIa showing numerous CD34 positive immunoreactive cells in renal interstitium (curved arrows) mainly near glomeruli (x200). (E): higher magnification of the previous figure showing many CD34 positive immunoreactive cells They appear branched with brown cytoplasmic immunoreaction \&rounded nuclei (curved arrows) (x 1000). (F): subgroup ПIb showing few CD34 positive immunoreactive cells in renal interstitium (curved arrow). Positive cytoplasmic immunoreactivity is seen in endothelial cells lining glomerular (green arrow) and peritubular capillaries (red arrow)

$(\mathrm{x} 200)$ 


\section{DISCUSION}

In this study, normal urea and creatinine levels went parallel with normal histological picture and morphometric results to reveal normal kidney function in control rats. As the laboratory precedes pathological findings, they were measured on $0,1,2 \& 7$ days $^{[12]}$. Measurement of serum urea and creatinine is used as a reliable indicator for renal functions assessment, significant elevation of serum urea and creatinine levels in group II confirmed the occurrence of renal dysfunction and was similarly reported by an earlier work ${ }^{[13]}$

In the present study, renal sections with H\&E staining of IRI group revealed various degrees of degenerative changes in MRCs as asymmetrical shapes and sizes. Other glomeruli showed low cellularity, partial or complete loss of capillary tuft and wide distorted Bowman's spaces. These results were furtherly supported by morphometric and statistical analysis which proved a significant increase in the mean numbers of the affected glomeruli. These findings were in accordance with earlier studies ${ }^{[6,14]}$.

In subgroup IIa, H\&E stained cortical and medullary tubular epithelial cells exhibited vacuolated cytoplasm, which could be considered as a sign of necrosis. Nuclei of many tubular cell appeared dark (pyknosis), fragmented (karyorrhexis) or with peripheral chromatin condensation which could be considered as histological features indicative of apoptosis ${ }^{[15]}$. IRI has been documented to cause mitochondrial swelling and loss of membrane potential, which contributes to both necrotic and apoptotic forms of cell death ${ }^{[16]}$. Accumulated cellular debris and hyaline casts were also detected in tubular lumina. These findings were in agreement with an earlier study ${ }^{[6]}$. These findings were further explained by other investigators who mentioned that ischemia results in rapid loss of cytoskeletal integrity which leads to loss of cell junctions and loss of polarity with mislocalization of adhesion molecules and other membrane proteins such as $\beta$-integrins and $\mathrm{Na}+\mathrm{K}+\mathrm{ATPase}$ leading to epithelial tubular cell death and desquamation ${ }^{[17]}$. Hyaline casts seen in tubular lumina of this group could be clarified by the assumption of other researchers who postulated that, desquamated cells and their debris that detach from basement membrane combine with proteins present in tubular lumen such as Tamm-Horsfall protein (renal epithelial glycoprotein) and fibronectin to form casts that can obstruct the tubule ${ }^{[18]}$.

In this study, the peritubular capillary congestion and inflammatory cellular infiltration seen in the interstitium between the tubules of IRI group were in agreement with an earlier study which confirmed the occurrence of inflammatory response as a squeal of ischemia ${ }^{[19]}$. Some authors mentioned that inflammatory infiltrate is an important contributor to kidney injury as neutrophils attach to activated endothelium and accumulate particularly in peritubular capillary network of outer medulla, as early as 30 minutes after reperfusion. They produce proteases, myeloperoxidase, reactive oxygen species (ROS) and cytokines, which leads to increased vascular permeability and reduced tubular epithelial and endothelial cell integrity aggravating kidney injury ${ }^{[20]}$. All of these factors contribute to vascular congestion and interstitial edema.

Examination of PAS-stained sections of non-treated IRI group (group II) in this work demonstrated partial or complete loss of brush border in most of tubular cells that was confirmed statistically. These findings were in line with an earlier study ${ }^{[21]}$. PAS stain was done to assess brush border preservation which is a highly sensitive marker for monitoring survival of proximal tubular cells, site where IR induced injury is most intense ${ }^{[7]}$, affecting sodium and glucose reabsorption in these tubules ${ }^{[22]}$.

In this study, extent of renal injury in non treated IRI group (group II) peaked after 48 hours in subgroup IIa then showed limited reduction after 1 week (subgroup IIb) with longer periods of reperfusion. Minimal improvement in kidney functions was evidenced by the non significant decrease in serum urea and creatinine levels in subgroup IIb compared to subgroup IIa. Also, limited restoration of renal structure in subgroup IIb was established by H\&E stain\& proved by non significant decrease in mean number of affected MRCs and non significant increase in mean area percent of PAS positive material compared to subgroup IIa. This might be attributed to the process of spontaneous repair in response to tubular injury. However, in severe ARF as in IRI, kidney's autoregenerative process may be inadequate for restoration of functional tissue resulting in permanent loss of renal function ${ }^{[23]}$.

On the other hand, rat received EPO in this study reported an improved kidney functions assessed by a significant decrease in serum urea and creatinine levels either on 2nd day (subgroup IIIa) or 7th day (subgroup IIIb). These results were consistent with an earlier work that declared that EPO injection ameliorate AKI and hasten functional recovery ${ }^{[2]}$. Also, histological architecture of MRCs, cortical and medullary tubules showed progressive improvement in subgroups IIIa \& IIIb. This was confirmed statistically by a significant decrease in the mean numbers of affected glomeruli. These results were further supported by PAS-stained sections 7 days after EPO therapy (subgroup $\mathrm{IIIb)}$ that exhibited preserved PAS positive brush border in most of cortical tubules and continuous basal laminae in nearly all tubules. Another prove came from Morphometric analysis that recorded a statistically significant increase in the mean area percent of PAS in subgroup IIIb when compared to other experimental subgroups. These results might suggest that administration of EPO immediately after bilateral IRI augmented functional and histological recovery ${ }^{[21]} \&$ consistent with an earlier work that declared that $\mathrm{EPO}$ injection ameliorate $\mathrm{AKI}^{[6]}$. 
Some workers recorded that bone marrow-derived stem cells(BMDCs) can contribute in regeneration of the renal tubular epithelium, differentiate into renal tubules, or promote proliferation of both epithelial and endothelial cells after acute injury ${ }^{[5]}$. The two subsets of BMDCs expressing CD34 are hematopoietic stem cells (HSCs) \& endothelial progenitor cells (EPCs) and are hypothesized to have a common precursor cell, hemangioblast ${ }^{[10]}$. Thus in this study,CD34 antibody was used as marker for the detection of both hematopoietic stem cells (HSCs) and endothelial progenitor cells (EPCs).

In this work, mean number of CD34 positive stem cells was only counted in renal interstitium. CD34 positive stem cells that appeared branched with brown cytoplasmic reaction and rounded nuclei increased in renal interstitium of all subgroups after IRI compared to control indicating that bone marrow derived CD34 positive stem cells are mobilized and recruited to the injured kidney. These results were in accordance with Huls et al. ${ }^{[24]}$ who emphasized that mechanical stresses such as ischaemia and injury, are able to mobilize BMDCs.

As this study exhibited a significant increase in mean number of CD34 positive stem cells in EPO treated subgroup IIIa compared to group II and control. This indicates that EPO could efficiently mobilize stem cells from bone marrow and increase their homing to the injured renal tissue. The highest value for mean number of CD34 positive stem cells was detected in subgroup IIIa (EPO, 48 hours) then this value was gradually decreased through the 7 days in subgroup IIIb (EPO, 1 week) which could be explained by differentiation of CD34 positive cells and loss of their marker. This coincided with the explanation of other workers who stated that during the differentiation of HSCs, they lose CD34 marker and acquire other biochemical markers specific to a lineage ${ }^{[25]}$. This could provide an explanation for augmented functional and histological renal recovery after IRI in EPO treated group in this work.

Kidney peritubular microvasculature has received increasing attention recently, since this fragile vasculature may not regenerate normally following injury. This may predispose to chronic ischemia of kidney. It has been proposed that successful regeneration of peritubular capillaries following injury is the key in preventing $\mathrm{CKD}^{[22]}$. Therefore, mobilization of Endothelial Progenitor Cells (EPCs) may be a promising new treatment approach that could enhance the repair of damaged vessel segments ${ }^{[26]}$. Some workers recorded that administration of EPO was able to increase the number of CD34 positive stem cells in peripheral blood and increase their subsequent differentiation into cell phenotype with endothelial characteristics and thus contribute to preservation of renal microcirculation $^{[27]}$.
Erythropoietin profoundly increases the number of circulating EPCs by mobilizing bone marrow derived hematopoietic stem cells ${ }^{[28]}$. Another study demonstrated that, treatment with EPO exert tissue-protective effects against IRI. They attributed these effects to mobilization of bone marrow endothelial progenitor cells (EPCs) ${ }^{[29]}$.

Recruitment of progenitor cells from the bone marrow is dependent on the secretion of matrix metalloproteinase- 9 by stromal cells in the bone marrow. Interestingly, mice lacking endothelial nitric oxide synthase failed to upregulate matrix metalloproteinase- 9 and are incapable of EPCs mobilization ${ }^{[30]}$. Therefore, one mechanism by which EPO can mobilize EPCs is through the release of nitric oxide ${ }^{[31]}$.

Alternatively, EPO may directly drive the differentiation of progenitor cell populations toward an endothelial cell phenotype. Researchers demonstrated that, recruitment and engraftment of vascular progenitor cells to injured or ischaemic tissue is a multi-step process that includes adhesion of the bone marrow-derived cells to the endothelium, transendothelial migration, chemotaxis, matrix degradation and invasion and in situ differentiation ${ }^{[32]}$.

Another study demonstrated that EPCs home into the post-ischemic tissue where they release different proangiogenic mediators such as vascular endothelial growth factor, hepatocyte growth factor, and insulin-like growth factor. These substances promote a faster recovery of damaged endothelial cells ${ }^{[33]}$.

The importance of the renal microvasculature as a defense mechanism against progressive renal damage and the recent observations that EPCs may function as endogenous regenerating system of the microvasculature suggest that EPC-based therapy represents a potential therapeutic option in renal disease ${ }^{[34]}$. Such therapeutic strategies aim at enhancement of EPC mobilization, recruitment and homing ${ }^{[35]}$. Endothelial progenitor cells stimulation by administration of EPO or analogues could be a new promising therapeutic strategy in regenerative cardiovascular medicine ${ }^{[36]}$.

The present study showed that CD34 positive stem cells were capable of mobilization \& homing into the IRI site in the presence of exogenously applied EPO making HSPCs \& EPCs readily available, and strengthening the rationale of clinical cellular therapy.

\section{CONFLICT OF INTEREST}

The authors have no conflicting financial interest. 


\section{REFERENCES}

1. Munshi R, Hsu C, Himmelfarb J. Advances in understanding ischemic acute kidney injury. BMC Medicine 2011; 7015: 9- 11

2. Moore E and Bellomo R. Erythropoietin (EPO) in acute kidney injury. Ann Intensive Care 2011; 1 - 3

3. Ishani A, Xue JL, Himmelfarb J, Eggers PW, Kimmel PL, Molitoris BA, Collins AJ. Acute kidney injury increases risk of ESRD among elderly. J Am Soc Nephrol 2009; 20: 223- 28

4. Sagrinati C, Ronconi E, Lazzeri E, Lasagni L, Romagnani P. Stem-cell approaches for kidney repair: choosing the right cells. Trends Mol Med 2008; 14: 277- 85

5. Maeshima A, Nakasatomi M, Nojima Y. Regenerative medicine for the kidney: renotropic factors, renal stem/progenitor cells, and stem cell therapy. Biomed Res Int 2014; 23: 661- 73

6. Johnson DW, Vessy DA, Gobe C. Erythropoietin protects against acute kidney injury and failure. The Open Drug Discovery Journal 2010; 2: 8 -17

7. Lange $\mathrm{C}$, Togel $\mathrm{F}$, Ittrich $\mathrm{H}$, Clayton $\mathrm{F}$, NolteErnsting C, Zander AR, Westenfelder C. Administered mesenchymal stem cells enhance recovery from ischemia/reperfusion-induced acute renal failure in rats. Kidney Int 2005; 68: $1613-7$

8. Hassoun HT, Lie ML, Grigoryev DN, Liu M, Tuder RM，Rabb H. Kidney ischemia-reperfusion injury induces caspase-dependent pulmonary apoptosis. Am J Physiol Renal Physiol 2009; 297: 125 -37

9. Kiernan JA. Histological and Histochemical Methods: theory and practice. $3^{\text {rd }}$ edition. Arnold publisher. London, New York \& New Delhi 2001: 111 -62

10. Boilson BA, Kiernan TJ, Harbuzariu A, Nelson RE, Lerman A, Simari RD. Circulating CD34+ cell subsets in patients with coronary endothelial dysfunction. Nat Clin Pract Cardiovasc Med 2008; 5:489 -96

11. Bancroft JD, Gamble M. Theory and Practice of Histological Techniques. $7^{\text {th }}$ edition, staining methods, Churchill Livingstone, Edinburgh, London, Madrid, Melbourne, New York and Tokyo 2008: 263- 325

12. Thompson CS. Diabetic nephropathy: treatment with phosphodiestrase type 5 inhibitors. World J Diabetes 2013; 4: 124- 9

13. Nitescu N, Ricksten SE, Marcussen N, Haraldsson B, Nilsson U, Basu S, Guron GN. Acetyl cysteine attenuates kidney injury in rats subjected to renal ischaemia-reperfusion. Nephrol Dial
Transplant 2006; 21: 1240- 7

14. Kiris I, Kapan S, Kilbas A, Yilmaz N, Altuntaş I, Karahan N, Okutan H. The protective effect of erythropoietin on renal injury induced by abdominal aortic-ischemia-reperfusion in rats. J Surg Res 2008; 149: 206- 13

15. Newman M. Cells Tissues and Organs. In Fundamentals of Ecotoxicology: The Science of Pollution, $4^{\text {th }}$ Edition CRC Press, 2014: 209- 34.

16. Sharples EJ, Patel N, Brown P, Stewart K, MotaPhilipe H, Sheaff M, Kieswich J, Allen D, Harwood S, Raftery M, Thiemermann C, Yaqoob MM. Erythropoietin protects the kidney against the injury and dysfunction caused by ischemia-reperfusion. J Am Soc Nephrol 2004; 15:2115- 24

17. Bonventre JV and Yang L. Cellular pathophysiology of ischemic acute kidney injury. J Clin Invest 2011; 121: 4210- 21

18. Zuk A, Bonventre JV, Matlin KS. Expression of fibronectin splice variants in the postischemic rat kidney. Am J Physiol Renal Physiol 2001; 280: 1037

19. Molina A, Ubeda M, Escribese MM, García-Bermejo L, Sancho D, Pérez de Lema G, Liaño F, Cabañas C, Sánchez-Madrid F, Mampaso F. Renal ischemia/ reperfusion injury: functional tissue preservation by anti-activated $\beta 1$ integrin therapy. J Am Soc Nephrol 2005; 18: 374-82

20. Jang HR and Rabb H. The innate immune response in ischemic acute kidney injury. Clin Immunol 2009; 130: $41-50$

21. Oba S, Suzuki E, Nishimatsu H, Kumano S, Hosoda C, Homma Y, Hirata Y. Renoprotective effect of erythropoietin in ischemia/reperfusion injury: possible roles of the Akt/endothelial nitric oxide synthasedependent pathway. Int J Urol. 2012; 19:248- 55

22. Ustundag S, Yalcin O, Sen S, Cukur Z, Ciftci S, Demirkan B. Experimental myoglobinuric acute renal failure: The effect of vitamin C. Ren Fail 2008 ; 30: 727- 35

23. Togel F, Isaac J, Westenfelder C. Hematopoietic stem cell mobilization-associated granulocytosis severely worsens acute renal failure. J Am Soc Nephrol 2004; 15: $1261-7$

24. Huls M, Russel FG, Masereeuw R. Insights into the role of bone marrow-derived stem cells in renal repair Kidney Blood Press Res 2008; 31: 104-110 
25. Devine H, Tierney K, Schmit-Pokorny K, McDermott $\mathrm{K}$. Mobilization of hematopoietic stem cells for use in autologous transplantation. Clin J Oncol Nurs. 2010; 2: $212-22$

26. Goligorsky MS, Kuo MC, Patschan D, Verhaar MC. Review article: endothelial progenitor cells in renal disease. Nephrology (Carlton) 2009; 14: 291- 7

27. Aydin Z1, Duijs J, Bajema IM, van Zonneveld AJ, Rabelink TJ. Erythropoietin, progenitors, and repair. Kidney Int Suppl. 2007; 107: 16- 20

28. Heeschen C1, Aicher A, Lehmann R, Fichtlscherer S, Vasa M, Urbich C, Mildner-Rihm C, Martin H, Zeiher AM and Dimmeler S. Erythropoietin is a potent physiologic stimulus for endothelial progenitor cell mobilization. Blood 2003; 102: 1340- 46

29. Nandra KK, Collino M, Rogazzo M, Fantozzi R, Patel NS, Thiemermann C. Pharmacological preconditioning with erythropoietin attenuates the organ injury and dysfunction induced in a rat model of hemorrhagic shock. Dis Model Mesh 2013; 6: 701 -9

30. Aicher A, Heeschen C, Mildner-Rihm C, Urbich C, Ihling C, Technau-Ihling K, Zeiher AM, Dimmeler S. Essential role of endothelial nitric oxide synthase for mobilization of stem and progenitor cells. Nat Med 2003; 9: 1370- 76 .

31. Bahlmann FH, De Groot K, Spandau JM, Landry AL, Hertel B, Duckert T, Boehm SM, Menne J, Haller H, Fliser D. Erythropoietin regulates endothelial progenitor cells. Blood 2004; 103: 921- 26.

32. Chavakis E, Urbich C, Dimmeler S. Homing and engraftment of progenitor cells: a prerequisite for cell therapy. J Mol Cell Cardiol 2008; 45: 514- 22.

33. Patschan D, Patschan S, Muller GA. Inflammation and microvasculopathy in renal ischemia reperfusion injury. J Transplant. 2012; 764154.

34. Baylis C. Nitric oxide deficiency in chronic renal disease. Eur J Clin Pharmacol 2006; 62: 123- 30.

35. Togel F, Isaac J, Hu Z, Weiss K, Westenfelder C. Renal SDF-1 signals mobilization and homing of CXCR4 positive cells to the kidney after ischemic injury. Kidney Int 2005; 67: 1772- 84

36. Mcneill B, Tiwari-Pandey R, Ruel M, Suuronen EJ Biomaterials for enhancing endothelial progenitor cell (EPC) therapy for cardiac regeneration. In: Cardiac Regeneration and Repair. Li RK, Weisel RD, editor. Woodhead: 2014. 82- 109 


\section{الملخص العربي}

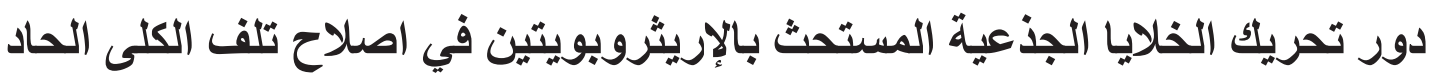

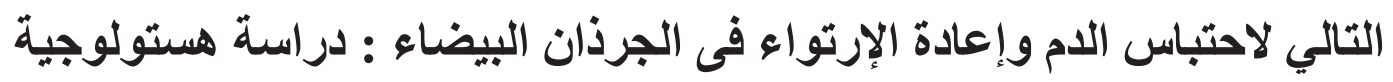 سمير محمود ندا ، نجوى عبد الوهاب أحمد ، إيمان عباس فرج ، رقية محمد حسن قسم الهستولوجيا ــ كلية الطب - جامعة القاهرة}

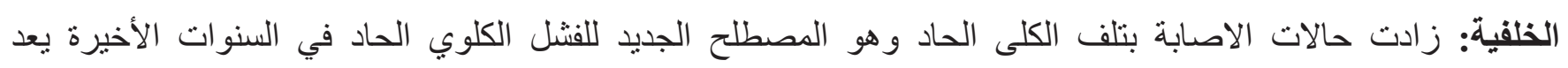

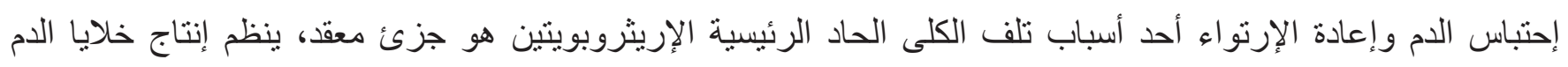

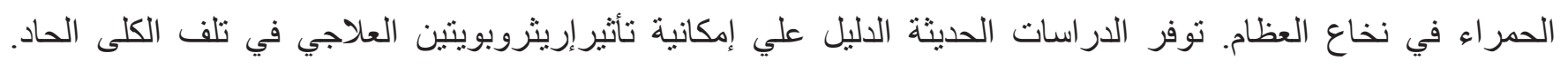
الهاف من العمل: بحث دور الإريثروبويتين فى تحريك الخلايا الجذعية الدثتقه من نخاع العظام ودوره في إصلاح تلف الكلى الحاد. المواد وطرق البحث: تضمنت هذه الدر اسة ب ك ذكر بالغ من الجرذان البيضاء ، مقسمة إلى ثلاث مجمو عات، الضابطة ، إحتباس الدم الدما

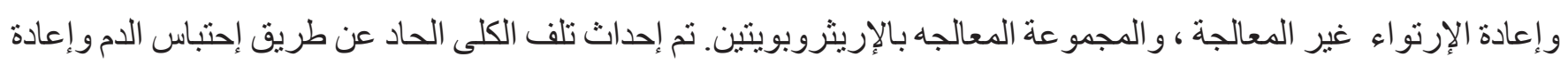

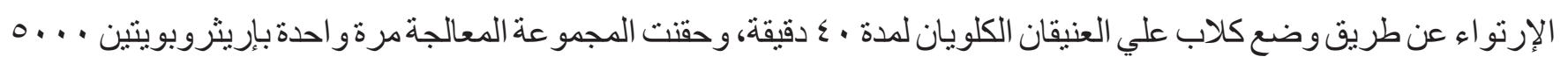

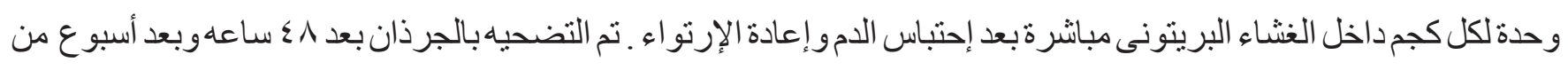

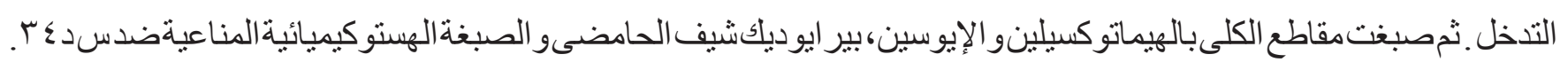
النتائج: حسن إريثروبويتين ضعف مظاهر الكلى التي وقعت من قبل إحتباس الدم وإعادة الإرتواء

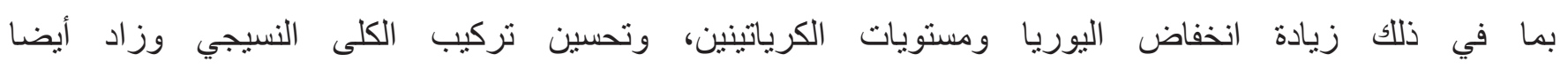
الخلايا الجذعبة الموجبة مناعيا ل س دئب المكونة للام و الخلايا السلفية المبطنة للأوعية الدموية.

الخلاصة: استتنج هذا العمل أن إعطاء إريثروبويتين في وقت إحتباس الدم وإعادة الإرنواء

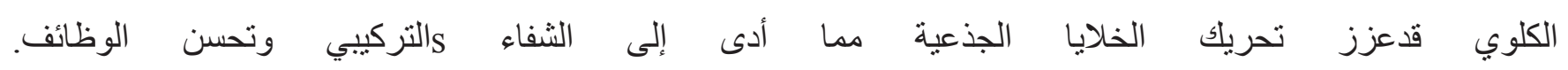

